\title{
The Effect of Static Stretching in Agility and Isokinetic Force at Football Players
}

\author{
Sami Sermaxhaj \\ Universe College, Department of Physical Culture, Sport and Recreation, Prishtina, Kosovo \\ University of Montenegro, Faculty for Sport and Physical Education, Niksic, Montenegro \\ Fitim Arifi \\ Universe College, Department of Physical Culture, Sport and Recreation, Prishtina, Kosovo \\ AAB College, Faculty of Physical Education and Sport, Prishtina, Kosovo \\ Abedin Bahtiri \\ University of Montenegro, Faculty for Sport and Physical Education, Niksic, Montenegro
}

\begin{abstract}
A B S T R A C T
Cool Down is very important for the recuperation of a football player. The objective of this research is to prove the effect of recuperation with static stretching in agility and isokinetic force at the young football players. This research has taken place

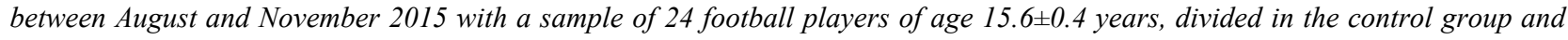
the experimental group. At first measurements have been initialed body weight $61.1 \pm 0.4 \mathrm{~kg}$ and body height $175.7 \pm 6.4 \mathrm{~cm}$, and agility (20 $\mathrm{m}$ zig-zag with and without ball) and isokinetic force (peak torque flexion and extension). Both groups of the football players have completed the regular training program. The experimental group (despite the control group) during the stage of recuperation (cool down), except the running with slow pace did also carry out the experimental program which did take place through static stretching. Experimental program consisted of 17 exercises bodily static stretching which are applied in the final training session (cool-down). After the experimental phase is finished the participants did undergo the final measures. The conducted results with univariate analysis of variance (ANOVA) in two tests (initial and final) have shown unimportant statistical values between the control group and the experimental one in the isokinetic force and agility. From the collected results we can conclude the recuperation with static stretching during the cool down has an unimportant statistical impact in the agility and isokinetic force of the young football players.
\end{abstract}

Key words: soccer players, recovery, static stretching, isokinetic strength, agility

\section{Introduction}

Football is a sport that is characterized by numerous and varied complex dynamic kinesiology activities that are characterized by a large number of cyclic and acyclic movements (Bjelica, Popović, \& Petković, 2013; Gardasevic, Bjelica \& Vasiljevic, 2016). The conditional preparation is the base to execute all the elements techno-tactical and responsible to differentiate between the high and low levels of the football players (Popović, Akpinar, Jakšić, Matić \& Bjelica, 2013; Popović, Bjelica, Jakšić \& Hadžić, 2014). During a football match the players carries out around 1200-1400 different moving activities from which 700-800 of those are movements with change in directions and only $11 \%$ of the total distance of these movements are executed with high intensity and important for the outcome of the match (Stolen, Chamari, Castanga \& Wilsloff, 2005). All these mentioned movements are closely linked with the production of dymanic force during the flexion and extension of the knee (Newman, Tarpenning \& Marino, 2004). So we can suppose that the isokinetic forces and agility are highly responsible or responsible for the taking of these actions in the football players.

Recuperation of organism is one of many important components to increase sport performance (Rey, Carlos, Luis \& Joaquin, 2012; Kinugasa \& Kilding, 2009; Tesitore, Meeusen,
Cortis \& Caprinica, 2007). The final cool-down phase of the training session is important to accelerate the recovery where activities like static stretching and running with slow tempo are typical for this part. Relaxation of the body is reached by extension static (static stretching), as one of the fundamental processes that is applied for prevention, and maintenance of physical performance components "recovery of the players" (Dawson, Gow, Modra, Bishop \& Stewart, 2005).

The static stretching for decades has been part of the warming up during the training but also during the competitions with the aim to raise flexibility and to prevent injuries etc. The execution of high number of movements with changing the pace and the direction of the movement, jumping, execution of technical elements, despite others is also depended on the flexibility of the locomotoric system (Gardasevic \& Bjelica, 2013). A number of researches carried out in the last decade have shown that the static stretching applied during the warming up has had an impact in lowering the performances in jumping, speed and agility (Behm, Chaouachi, Lau \& Wong, 2011; Gelen, 2010). The research that was carried out suggests that during the warming up should be applied exercises of dynamic flexibility combined with the static stretching exercises with controlled movements and a fully optimal amplitude (ROM) which are more effective in developing the flexibility and improvement of the explosive force of sprint (Andersen, 2005). 
All types of stretching are effective in growing the movement amplitude (Walker, 2006). Stretching after exercise is commended as a preventative measure for delayedonset muscle soreness and improved range on motion through dispersion of edema or tension reduction of the muscletendon unit (Montgomery et al., 2008). A research carried out with 26 football coaches of Mauritius Football Association (MFA), $76 \%$ of those think that stretching should be exercised three times a week during the "getting ready" period and 2 times during the week while in competition, especially from the regular sessions with duration of 0.6 to 1.3 hours a week (Kelly, Fawzi \& Rajiv, 2012).

The aim of this research was to prove the impact of the static stretching in the exercises which are applied during the phase of recuperation (cool down) in the agility and isokinetic force of the young football players under the age of 17. Agility in the football game is a form of exercise where a person provides running to change direction with and without ball (Popovic et al., 2014), and Isokinetics is a form of exercise where a person provides a maximum muscle contraction against a resistance or lever arm, (isokinetic dynamometer) at a fixed speed through a given range of motion. This type of muscle action can be done either concentrically or eccentrically at the given joint. Peak Torque is the greatest amount of force produced by a muscle (Kowalski, 2003). This can be determined within each repetition or the entire set. Peak Torque indicates the muscles maximum capability of developing force. This is also equivalent to a 1-repition maximum isotonic strength test. Peak torque is an absolute value (Kowalski, 2003). Static Stretch The technique of lengthening a muscle group by slowly moving a joint to its maximal range of motion and maintaining the position for a period of time (Guissard \& Duchateau, 2004).

\section{Methods}

In order to carry out this research, first of all the whole sample has carried out the medical check up at the medical sport centre in Prishtina and it has been proved that all the football players are healthy to participate in football, and in accordance with the Helsinki decleration, all the participants have been informed with the aim of the testing procedures and the experimental treatment.

\section{Participants}

In this study have participated twenty four young football players under the age of 17, part of the football school of the club Ramiz Sadiku from Prishtina which were under direction of a UEFA licensed coaches where they have carried out regular training sessions and champion competition in the elite league of football of Kosovo, in the first macrocycle (training sessions and competitions) of the autumn season from $1^{\text {st }}$ of August to $1^{\text {st }}$ of December 2015.

\section{Procedures}

Participants divided in the control group $(\mathrm{n}=12)$ and experimental $(n=12)$ have been compared in the initial tests and the anthropometrical final ones (height and body weight), motoric performance (agility and isokenentic force). All these measures have taken place in the the parquet flooring and the diagnostification lab of the Sports College Universi in Prishtina in the same time and date, from a specialized team. The initial testing took place before the beginning of the pre-season while the final testing was performed at the end of the season (after 4 months of intervenation with static stretching exercise). At the beginning of the study to all participants is measured body height $176.2 \pm 6.4$ $\mathrm{cm}$ (anthropometer of Martin) and body weight of $61.95 \pm 8.5 \mathrm{~kg}$ (In body 720). Average age of the participants in the initial measurements was 15.7 years. Football players in this study after the warming up, did go under agility test; test $20 \mathrm{~m}$ zig-zag with and without ball (Idrizovic, 2014) and isokinetic force; Peak Torque flexion and extension (Grbovič, 2013; Zakas, Doganis, Galazoulas \& Vamvakoudis, 2006; Dirnberger, Kösters \& Müller, 2012). On the parquet flooring, agility performances was performed and measured with New Test, i.e. Power timer 300 photocells with exact time of $0.01 \mathrm{sec}$. The isokinetic strength of the knee flexors and extensors (dominant leg) was measured in the diagnostification lab with the isokinetic dynamometer Biodex System 4. Isokinetic extension and flexion peak torque was measured at $120 \% \mathrm{~s}$ (degree/sec) in sitting position with a hip angle $100 \mathrm{de}-$ gree. Individual seat settings were stored in PC memory before measuring the leg and were automatically activated in the process of measuring and follow up-testing. At the beginning of the follow-up testing individual settings were rechecked and adjusted if necessary. The participants were instructed to hold the hand-grips located at the side of the seat during all testing efforts. During the testing procedure the players were provided with concurrent visual feedback in the form of an isokinetic strength curve displayed on the dynamometer monitor.

Participants of this research divided into two groups (control and experimental) during the period of August and November 2015 have exercised 3 times a week, in total doing 48 training sessions, under the plan and the program of the football school of the Ramiz Sadiku Club in Prishtina. Protocol of control group (general warm up 5-7 min, specific warm up 10-15 min, the main part 35-45 min, cool down 10 min recovery by running). Protocol of experimental group general warm up 5-7 min, specific warm up 10-15 min, the main part 35-45 min, cool down 10 min recovery with running and $15 \mathrm{~min}$ static stretching. The experimental group (compared to the control group) except the regular training, did undergo the experimental program (recuperation with static stretching) which has taken place during the cooling down phase. The experimental program was planned from the research author based on the recommendations of the authors of this field (Walker, 2006) and did involve 17 stretching exercises-static stretching; upper body-flexibility exercises (Neck stretch, Upper Back, Chest and Back, Shoulder and mid-upper Back, Shoulder and triceps, Lateral flexion right-left) and lower body flexibility exercises (Hamstring Two Leg Stretch, Achiles and Back Stretch, Quadriceps Stretch, Hamstring and Groin Stretch, Standing Groin Stretch, Groin Stretch, Chest Stretch, Sitting Hamstring Stretch, Lower Back Stretch, Two Legs Seat Hamstring Stretch, Achiles Tendon Stretch). Every exercise has been completed within the duration of 20 seconds.

\section{Statistical analysis}

Data analysis was performed using the Statistical Package for the Social Sciences (SPSS version 21.0). Mean and Standard Deviation (SD) were calculated for both groups in initial and final measurement for anthropometric (body height and body weight), agility performance (zig zag $20 \mathrm{~m}$ with and without ball), isokinetic force (peak torque flexion and extension). With univariate analysis of variance (ANOVA) were calculated differences between arithmetic means of control and experimental group before and after experimental programme (static stretching). The level of significant is $\mathrm{p}<0.05$.

\section{Results}

The descriptive parameters are displayed in Table 1. for both groups in initial measures. 
Table 1. The variables data of anthropometric (body height and body weight) and motoric performance (agility and isokinetic force) of the control and experimental group at the initial measurement

\begin{tabular}{lcccc}
\multicolumn{5}{c}{ force) of the control and experimental group at the initial measurement } \\
\hline Variable & $\begin{array}{c}\text { control group } \\
(\mathrm{M} \pm \mathrm{SD})\end{array}$ & $\begin{array}{c}\text { experimental group } \\
(\mathrm{M} \pm \mathrm{SD})\end{array}$ & $\mathrm{F}$ & $\mathrm{p}$-value \\
\hline Age (years) & $15.6 \pm 0.4$ & $15.9 \pm 0.6$ & - & - \\
Weight $(\mathrm{kg})$ & $61.1 \pm 10.2$ & $62.7 \pm 7.6$ & .181 & .675 \\
Height $(\mathrm{cm})$ & $175.7 \pm 6.4$ & $176.7 \pm 6.7$ & .141 & .711 \\
20 m zig-zag without ball & $6.47 \pm 0.3$ & $6.50 \pm 0.4$ & .028 & .868 \\
20 m zig-zag with ball & $7.99 \pm 0.6$ & $7.97 \pm 0.4$ & .013 & .912 \\
peak torque flexion & $76.66 \pm 28.8$ & $82.80 \pm 20.1$ & .364 & .552 \\
peak torque extension & $109.30 \pm 30.1$ & $99.97 \pm 20.2$ & .281 & .601 \\
\hline
\end{tabular}

The results of the anthropometric measures in the Table 1. show that with the univariate analysis of variance (ANOVA) based on the coefficient F-relations and the value of the statistical significane $\mathrm{p}$-value have been proved that there are unimportant statstical differences between the control group and the experimental one, which does prove the homogenity of the groups in the initial measures of the main anthropometric parameters (body weight and height) and motoric performance; agility test (20 m zig-zag with and without ball) and isokinetic force (peak torque flexion and extension) at the football players under the age of 17.

Table 2. The significance of differences between arithmetic means of variables data of anthropometric (body height and body weight) and motoric performance (agility and isokinetic force) of the control and experimental group at the final measurement

\begin{tabular}{lcccc}
\hline Variable & $\begin{array}{c}\text { control group } \\
(\mathrm{M} \pm \mathrm{SD})\end{array}$ & $\begin{array}{c}\text { experimental group } \\
(\mathrm{M} \pm \mathrm{SD})\end{array}$ & $\mathrm{F}$ & p-value \\
\hline Age (years) & $15.9 \pm 0.4$ & $16.2 \pm 0.6$ & - & - \\
Weight $(\mathrm{kg})$ & $62.2 \pm 8.8$ & $64.0 \pm 8.0$ & .288 & .597 \\
Height $(\mathrm{cm})$ & $177.1 \pm 6.5$ & $177.6 \pm 6.7$ & .043 & .838 \\
20 m zig-zag without ball & $6.23 \pm 0.3$ & $6.16 \pm 0.3$ & .324 & .575 \\
20 m zig-zag with ball & $7.73 \pm 0.5$ & $7.73 \pm 0.4$ & .000 & .997 \\
peak torque flexion & $115.41 \pm 29.9$ & $130.98 \pm 29.8$ & 1.628 & .215 \\
peak torque extension & $120.27 \pm 30.3$ & $126.48 \pm 26.9$ & .790 & .384 \\
\hline
\end{tabular}

The reults of the agility and isokinetic force performances have been shown in the Table 2. and show that with univariate analysis of variance (ANOVA) based on the coefficient F-relations and the value of statistical importance (significant) $\mathrm{p}-$ value have been proved unimportant statistical differences in the final testings anthropometric parameters (body weight and height), motoric performance; agility test ( $20 \mathrm{~m}$ zig-zag with and without ball) and isokinetic force (peak torque flexion and extension) at the football players under the age of 17 .

The given results do prove that the experimental programme (static stretching exercises) have not had any impacts in diferentiating between the groups in the final measurses variables of the agility and isokinetic force.

Although a great number of studies have focused on researches of training programs for improving of agility (Behm et al., 2011; Milanovic, Sporišs, Trajkovic, James \& Samija, 2013) and isokinetic strength of knee flexors and extensors (Gioftsidou et al., 2008; Lehnert, Psotta, Chvojka \& Croix, 2014). The static stretching is still one of the main discussions in sport and medicine. Stretching should be applied during the cooling down session or the warming up session, to stimulate the motoric performances to prevent the injuries, or for other reasons, so, there are different thoughts that exist in what form and when, the application of the stretching exercises do have an impact in favor or not in favor in the anthropologic status of the football players. From a lot of researchers it has been proved that the exercises of the static stretching applied in the warming up session have a negative impact with an statistical importance in the speed, agility and the explosive force of the football players (Gelen, 2010; Brandey, Ajit, Richard \& Jennifer, 2012; Haddad et al., 2014). Compared to the mentioned researches above, some researches have researched in the impact of the combined stretching (dynamic and static) and have not proved any determinant impacts in the motoric performances: speed and agility
(Behm et al., 2011). In the last decade the impact of the static stretching in the motoric performance applied in the warming up session has been researched from a lot of medicine researches. But the main reason for this study is that numerous researches have shown that static stretching can decrease soccer performance especially agility with and without ball and isokinetic force during knee extension and flexion (isokinetic peak torque) in the youth soccer players. Wrigley (2000) suggested that isokinetic testing of knee flexor and extensors is reliable and sensitive enough to explore seasonal changes in soccer players.

The results according to the univariate analysis of variance (ANOVA) have shown that the static stretching exercises applied at the end of the training session "cool down" have had no important impact in the agility and isokinetic force of the football players under the age of 17. Details of results of the tests for agility and isokinetic force (peak torque flexion and extension) do reflect statistically unimportant differences among the control and experimental group at initial and final tests, thus suggesting that static stretching exercises during the cool down have no significant effect on motoric performance (agility and isokinetic force) of the football players under the age of 17 .

\section{Discussion}

In this research it has been proved that the static stretching exercises applied 3 times a week during the cooling down period, in a duration of 16 weeks did not have any important statistical effect in the testing of the agility and isokinetic force at the football players U17. We can conclude that the static stretching exercise applied in the end of the training sessions (cool down) do not have any impact in the agility and isokinetic force of the young football players. So at the young football 
players we can recommend the application of the static stretching in the end of the training session 2-3 times a week or also in the special training sessions with the objective to raise the optimal flexibility of the body as one of the pre conditions to execute the speed movements, agility, coordination, explosive force and the execution of the technical elements of the football match. These results can be used to fill in the existing knowledge of the impact of the static stretching in the cool down at the young football players in the performances of the agility and isokinetic force and to rationalise the processes when it comes to the plan and program content of the training sessions.

Furthermore the results of this study can be used as an in-

\section{R E F E R E N C E S}

Andersen, J.C. (2005). Stretching before and after exercise: Effect on muscle soreness und injury risk. Journal of Athletes Training, 40, 218-220.

Behm, D.G., Chaouachi, A., Lau, P.W.C., \& Wong, D.P. (2011). Short durations of statik stretching when combined with dynamic stretching do not impair repeated sprints and agility. Journal of Sports Science and Medicine, 10(2), 408+.

Bjelica, D., Popović, S., \& Petković, J. (2013). Comparison of Instep Kicking Between Preferred and Non-Preferred Leg in Young Football Players. Montenegrin Journal of Sports Science and Medicine, 2(1), 5-10.

Brandey, J., Ajit, D.K., Richard, S.F., \& Jennifer, L.C. (2012). Acute effects of statik and proprioceptive neuromusscular Fascilitation Stretching on Agility performance in Elite Youth Soccer Players. International Juranal Exercises Sciences, 5(2), 97-105.

Dawson, B., Gow, S., Modra, S., Bishop, D., \& Stewart, G. (2005). Effects of immediate post-game recovery procedures on muscle soreness, power and flexibility levels over the next 48 hours. J Sci Med Sport, 8, 210- 221.

Dirnberger, J., Kösters, A., \& Müller, E. (2012). Concentric and eccentric isokinetic knee extension: A reproducibility study using the IsoMed 2000-dynamometer. Isokinetics and Exercise Science, 20(1), 31-35.

Gardasevic, J., Bjelica, D., \& Vasiljevic, I. (2016). Six-Week Preparation Period and its Effects on Transformation Movement Speed ëith Football Players under 16. Sport Mont, 14(1), 13-16.

Gardasevic, J., \& Bjelica, D. (2013). Efekti programiranog trenažnog rada u trajanju od šest nedjelja na transformaciju fleksibilnosti kod fudbalera kadetskog uzrasta. Sport Mont, 37,38,39/XI, 212-217.

Gelen, E. (2010). Acute effects of different warm-up methods on sprint, slalom dribbling, and penalty kick performance in soccer players. $J$ Strenth Cond Res, 24(4), 950-956.

Gioftsidou, A., Ispirlidis, I., Pafis, G., Malliou, P., Bikos, C., \& Godolias, G. (2008). Isokinetic strength training program for muscular imbalances in professional soccer players. Sport Sciences for Health, 2(3), 101-105.

Grbovič, M. (2013). Merenje agilnosti u različito definisanim uslovima. Doktorska disertacija, Beograd: Fakultet sporta i fizičkog vaspitanja.

Guissard, N., \& Duchateau, J. (2004). Effect of static stretch training on neural and mechanical properties of the himan plantar-flexor muscles. Muscle and Nerve, 29, 248-255.

Haddad, M., Dridi, A., Chtara, M., Chaouachi, A., Wong, P., Behm, D., \& Chamari, K. (2014). Static stretching can impair explosive performance for at least 24 hours. The juar- centive to research the impact of the static stretching in the cool down and other characteristics of the anthropologic status (morphologic characteristics, other motoric performances, functional, psychological, rehabilitation, recuperation, prevention of injuries, demonstration of the technical elements.

\section{Acknowledgements}

The researchers are grateful to Abedin Bahtiri from the Kolegj Universi Pristina for his contribution for organizing the measurements.

nal of Strength \& Conditioning Ressearch, 28(1), 140-146.

Idrizovic, K. (2014). Physical and anthropometric profiles of elite female soccer players. Medicina dello sport, 67(2), 273-287.

Kelly, C., Fawzi, M., \& Rajiv, V. (2012). Streching in the prevention of hamstring strains: Attitudes, beliefs and current practices amaong football coaches in Mauritius. Open Juarnal of preventive Medicine, 2, 141-148.

Kinugasa, T., \& Kilding, A.E. (2009). A comparison of postmatch recovery strategies in youth soccer players. $J$ Strength Cond Res, 23, 1402-1407.

Kowalski, C.A. (2003). Correlation between time to peak torque and peak torque to vertical jump in college age athlete. Master's Thesis, Marshal University.

Lehnert, M., Psotta, R., Chvojka, P., \& Croix, M. (2014) Seasonal variation in isokinetic peak torque in youth soccer players. Kinesiology, 46(1), 79-87.

Milanovic, Z., Sporiš, G., Trajkovic, N., James, N., \& Samija, K. (2013). Effect of a 12 Week SAQ Training Programme on Agility with and without the Ball among Young Soccer Players. Jurnal of Sports Sciences and Medicine, 12, 97103.

Montgomery, P., Pyne, D., Hopkins, W., Dorman, J., Cook, K., $\&$ Minahan, C. (2008). The effect of recovery strategies on physical performance and cumulative fatigue in competitive basketball. Juarnal Sports Sciences, 26, 1135- 1145.

Newman, M.A., Tarpenning, K.M., \& Marino, F.E. (2004). Relationships between isokinetic knee strength, single sprint performance, and repeated-sprint ability in football players. Journal of Strength and Conditioning Research, 18, 867872.

Popović, S., Bjelica, D., Jakšić, D. \& Hadžić, R. (2014). Comparative Study of Anthropometric Measurement and Body Composition between Elite Soccer and Volleyball Players. International Journal of Morphology, 32(1), 267-274.

Popović, S., Akpinar, S., Jakšić, D., Matić, R. \& Bjelica, D. (2013). Comparative Study of Anthropometric Measurement and Body Composition between Elite Soccer and Basketball Players. International Journal of Morphology, 31(2), 461-467.

Rey, E., Carlos, L.P., Luis, C., \& Joaquin. L.B., (2012). The Effect of Immediate Post-Training Active and Passive Recovery Interventions on Anaerobic Performance and Lower Limb Flexibility in Professional Soccer Players. Journal of Human Kinetics, 31, 121-129.

Stolen, T., Chamari, K., Castanga, C., \& Wilsloff, U. (2005). Physiology of soccer. J Sports Med., 35(6), 501-536.

Tesitore, A., Meeusen, R., Cortis, C., \& Caprinica, L. (2007). Effects of different recovery interventions on anaerobic per- 
formances following preseason soccer training. Journal of Strength and Conditioning Research, 21(3), 745-750.

Walker, B. (2006). The anatomy of stretching. Chichester: Lotus.

Wrigley, T.W. (2000). Assessment for football: soccer, Australian rules, and American. In L.E. Brown (Ed.). Isokinetics in human performance, 407-428.

Zakas, A., Doganis, G., Galazoulas, C., \& Vamvakoudis, E. (2006). Effect of acute static stretching duration on isokinetic peak torque. Pediatr. Exerc. Sci., 18, 252-261.

\section{S. Sermaxhaj}

University of Montenegro, Faculty for Sport and Physical Education, Narodne omladine bb, 81400 Niksic, Montenegro e-mail: sermaxhajsami@live.com 
